\title{
LAS TRAMAS DE LA HETERONORMATIVIDAD \\ Y EL PATRIARCADO: 1977, DE PEQUE VARELA
}

\author{
Ángeles Mateo del Pino \\ Universidad de Las Palmas de Gran Canaria \\ angeles.mateo@ulpgc.es
}

En 2007 se estrenó el cortometraje de animación 1977, de Peque Varela ${ }^{1}$. Una directora nacida en Ferrol, pero radicada en Londres, ciudad en la que se graduó como directora de animación en el National Film and Television School. Como trabajo fin de título presentó su corto 1977, con el cual obtiene reconocimiento nacional e internacional. Numerosos han sido los premios recibidos, además de participar en festivales tan prestigiosos como Sundance Film Festival y ClermontFerrand International Short Film Festival. Desde el año 2005 trabaja como directora y animadora independiente en publicidad, realizando diversos encargos, varios de ellos para la MTV, y montando títulos de crédito, como el que llevó a cabo para el film de Tim Burton Sweeney Todd. The Demon Barber of Fleet Street (2007). En 2009, junto con la productora argentina Silvina Cornillon, funda Argallando, una compañía de producción independiente. El primer proyecto de animación de este estudio fue el cortometraje Gato encerrado (2010).

1977 es el año elegido por Peque Varela para titular su corto. No es gratuita esta fecha, ya que se corresponde con su nacimiento, lo que dota de carácter autorreferencial a su obra. Llama la atención el componente simbólico que gravita sobre este relato visual desde el inicio, ya que comienza con la alusión a unas fiestas propias de un pueblo, lo que nos remite a la tradición, en este caso baile y canto popular, unas muñeiras gallegas. Una tradición que debemos leer como transmisión, un legado que se conserva y se traspasa y que, como veremos más adelante, no hace más que presagiar ese "patrimonio" o cúmulo de enseñanzas, doctrinas, costumbres, normas que heredamos y que, como advierte Foucault (Vigilar), ejercen sobre la sociedad un poder de control y disciplina.

Este vónos o reglas consuetudinarias que se establecen por la fuerza de la costumbre son deudoras de la época en la que se gestan, por lo que devienen convenciones sociales, proyectando estereotipos y prejuicios. Tal es lo que ocurre a esta "niñx garabato», quien en el patio del colegio no se distingue del resto, todas y todos uniformados con las batas escolares, homogeneización que va más allá de la ropa y que tiene que ver con esa función de encauzar la conducta, tecnologías coercitivas o estrategias para no diferenciar rasgos y comportamientos particulares, propias de las instituciones disciplinarias como son las escuelas, además de otras -dirá Foucault (Vigilar) - como las prisiones, los hospitales, los cuarteles, los psiquiátricos... Cuando los muros del colegio se rompen y nuestro personaje sale al mundo acompañada

DOI: https://doi.org/10.25145/j.clepsydra.2021.21.14

Revista Clepsydra, 21; marzo 2021, pp. 305-308; ISSN: e-2530-8424 
de una pelota, símbolo de libertad, se verá coartada por una convención social o estereotipo de género, se le asigna un vestido rosa: «ante la sociedad será una nińa y deberá comportarse como tal». En este momento, comienza a bullir en su interior un nudo, un nodus difícil de desatar, que podemos interpretar como esa disidencia que comienza a surgir en su interior, manifestación de un sentirse ajena, de un querer y no poder contravenir la norma, disyuntiva que nos remite a la sujección/ subordinación, a ese «sujeto sujetado» del que habla Judith Butler (Mecanismos 22-29). $\mathrm{Si}$ antes la pelota la hacía liberarse, ahora será un lápiz -en el que no gratuitamente se lee "made in casa», de nuevo la tradición, lo familiar y conocido- el que pueda emanciparla. Sin embargo, la letra deberá amoldarse a unos cuadernos pautados: «Los árboles son altos». Su escritura «desviada», símbolo identitario, no encaja en esos renglones. De nuevo el nudo hace acto de presencia.

La nińa ha crecido, su padre la recoge del colegio, juntos se trasladan por la ciudad, recorriendo carreteras que se revelan como un espacio organizado, como un Monopoly. Un tablero dividido en casillas en las que se lee: «Día del padre». «Es su cumpleaños». Calles vacías, en las que solo se divisa un grupo de muchachos, imagen de un dominio público que pertenece al orden masculino y en el que también podemos adivinar esa espacialización, a la que alude Diana Fuss (113), o «lógica de los límites, márgenes, fronteras y lindes» del adentro y del afuera. En este caso el afuera, como espacio de lo público, de lo laboral y lo social, se identifica con el orden masculino, y el adentro, ámbito de lo doméstico, familiar y privado, se corresponde con el orbe femenino. Binarismo masculino/femenino sobre el cual se asienta la cultura occidental.

En este recorrido, otra parada tiene lugar, en este caso en una institución educativa, que se puede interpretar como el instituto. Una "nueva ella» hace acto de presencia, ejemplificación de esa performatividad de género sobre la que teorizó Butler (Género en disputa) y que se materializa en el cortometraje como un juego preestablecido: Insert Coin. La pizarra de la clase muestra el mundo de la lógica, de las matemáticas, del raciocinio: Resta/divide/multiplica. Matemáticas que dejan paso a esa otra supuesta lógica del género. El deporte, particularmente el fútbol, ha sido considerado un orbe masculino, por lo que el personaje es desplazado al ámbito cerrado y estático del futbolín. Se revela entonces como un ser abyecto, desviado, lo que implica no solo a la esfera del deporte, sino al universo de los afectos y los placeres, de las prácticas e identidades sexuales, pues no se ajusta a un determinado modelo heterosexual. Tal confinamiento supone una abyección; «una expulsión radical del espacio de la humanidad legítima. Y supone, consecuentemente, la constitución de un espacio inhabitable» (Llamas 7-8). En este sentido, Ricardo Llamas sigue muy de cerca lo esbozado por Judith Butler. Para la filósofa estadounidense la

${ }^{1}$ Reino Unido / España / 2007 / 9 min / 35mm 16/9 / Color. Dirección Peque Varela. Producción Gavin Humphries (National Film and Television School) \& Quark Films. Fotografía Neus Olle-Soronellas. Edición Fiona De Souza. Diseño sonido Chu-Li Shewring. Compositor Natalie Holt. Animadores Peque Varela / Kaori Hamilton / R. Vetusto. 
abyección (ab-jectio) implica la acción de arrojar fuera, desechar, excluir; por lo tanto, lo degradado o eliminado dentro de los términos de la socialidad marca la diferencia. Lo abyecto remite a "aquellas zonas "invivibles", "inhabitables" de la vida social que, sin embargo, están densamente pobladas por quienes no gozan de la jerarquía de los sujetos, pero cuya condición de vivir bajo el signo de lo "invivible" es necesaria para circunscribir la esfera de los sujetos» (Butler, Cuerpos 20). La lógica de la exclusión permite la existencia de lo abyecto (Kristeva 88). Algo que le hacen saber sus compañeras, quienes -cuales gallinas- cacarean al unísono: «machito», «marimacho». El peso del lenguaje y la coacción de las palabras. Entonces deberá elegir entre una bicicleta azul o rosa, estereotipos de género que asignan color a lo masculino frente a lo femenino. Si no opta por lo normativo la violencia se hará sentir. Como autómata, ser diagramado, decide la bicicleta rosa y con ella se mueve por esas calles-casillas, mientras de fondo se escucha una canción tradicional (el vónos), pero el rechazo de los otros se deja sentir una vez más: «Maricón». No responde al modelo. Un modelo ideal sexogenérico en el que los seres, cual Playmobils, desempeñan un rol asignado: ellas planchan, compran, hacen de madres. Ellos son astronautas, médicos o simplemente leen el periódico. Todo está diseñado de antemano, son los roles de género.

En medio de este diseño, por primera vez surge Peque, pero, aun cuando el personaje tiene rostro, su cuerpo «despuntado» no adquiere forma. La biología la dibuja metonímicamente, la parte por el todo, así afloran dos pechos y un aparato genital femenino: trompas de Falopio, ovarios, útero, cérvix, vagina y vulva. El poder de la sangre: «Ya es unha muller». Femenina engendradora, «bio-operaria productora de óvulos» (Preciado 13). Comienza entonces un nuevo juego, el de emparejar fichas. La adolescencia pone en acción el mito del amor romántico, esa construcción social de eros que se basa en la creencia de la media naranja (Herrera González). El uno necesita a la otra; la otra necesita al uno para fusionarse y completarse. Modelo de relación heterosexual. Las parejas van mostrándose: Paul y Anita. Alfred y Susan. Anne y Philip. ¡María y Claire!... Esta última no responde al paradigma de la heteronormatividad, ese régimen social, político y económico impuesto por el patriarcado, aun cuando María, performáticamente desempeñe el rol femenino impuesto y luzca sus aderezos: melena, pintalabios, rímel. Un simulacro que al caer desvela a Peque. El mundo, su mundo, se viene abajo. De nuevo aflora la violencia directa, verbal, las palabras peyorativas, la descalificación (Galtung). El nudo retorna, sin embargo, logra zafarse de ese entramado y aunque queda en pie la etiqueta de «marimacho», esta pierde su fuerza, pues la sujeto la despoja de su carga negativa, en una resignificación política del discurso (Butler, Cuerpos). Solo entonces el nudo cesa y las gaviotas, aquellas con las que se inicia el cortometraje, vuelven a hacer su aparición, mostrando otro horizonte, el de una nueva subjetividad: un ser no normativo que se aleja de los imperativos del sistema binario. El otrora sujeto abyecto se concibe ahora como una toma de posición respecto al orden simbólico y al propio cuerpo y parece dejar como lema aquellas palabras de Michel Foucault: «donde hay poder hay resistencia» (Historia 116). 


\section{BIBLIOGRAFÍA}

Butler, Judith. Mecanismos psíquicos del poder. Teoría sobre la sujeción. Madrid: Cátedra, 2001.

Butler, Judith. El género en disputa. El feminismo y la subversión de la identidad. México: Paidós, 2001.

Butler, Judith. Cuerpos que importan. Sobre los limites materiales y "discursivos» del sexo. Buenos Aires: Paidós, 2005.

Foucault, Michel. Historia de la sexualidad. 1. La voluntad de saber. Madrid: Siglo XXI Editores, 1992.

Foucault, Michel. Vigilar y castigar. Barcelona: Círculo de Lectores, 1999.

Fuss, Diana. «Dentro/Fuera», en Carbonell, Neus y Torras, Meri (eds.), Feminismos literarios. Madrid: Arco Libros, 1999, pp. 113-124.

Galtung, Johan. Tras la violencia, 3R: reconstrucción, reconciliación, resolución. Afrontando los efectos visibles e invisibles de la guerra y la violencia. Bilbao: Gernika Gogoratuz/Bakeaz, 1998.

Herrera Gómez, Carol. La construcción sociocultural del amor romántico. Madrid: Fundamentos, 2011.

Kristeva, Julia. Poderes de la perversión. México: Siglo XXI, 2004.

Llamas, Ricardo. Teoría torcida. Prejuicios y discursos en torno a la homosexualidad. Madrid: Siglo XXI Editores, 1998.

Preciado, Paul B. «Decimos revolución», en Solá, Miriam y Urko, Elena (eds), Transfeminismo. Epistemes, fricciones y flujos. Tafalla: Txalaparta, 2013, 9-13.

Varela, Peque. 1977. Dirección Peque Varela. Producción Gavin Humphries (National Film and Television School) \& Quark Films. Fotografía Neus Olle-Soronellas. Edición Fiona De Souza. Diseño sonido Chu-Li Shewring. Compositor Natalie Holt. Animadores Peque Varela / Kaori Hamilton / R. Vetusto. Reino Unido / España, 2007. 